\title{
Discussion: Size effect on compressive behaviours of normal-strength concrete cubes made from demolished concrete blocks and fresh concrete
}

\section{Chunhui Liu}

Doctor, Guangzhou University - Tamkang University Joint Research Centre for Engineering Structure Disaster Prevention and Control, Guangzhou University, Guangzhou, PR China

\section{Bo Wu}

Professor, State Key Laboratory of Subtropical Building Science, South China University of Technology, Guangzhou, PR China

\section{Yong Yang}

Professor, School of Civil Engineering, Xi'an University of Architecture and Technology, Xi'an, PR China

\section{Jose R. Martí-Vargas}

Professor, ICITECH, Institute of Concrete Science and Technology, Universitat Politècnica de València, Valencia, Spain

\section{Contribution by J. R. Martí-Vargas}

Based on interest in using demolished concrete blocks (DCBs), the paper by $\mathrm{Wu}$ et al. (2013) presents research on the uniaxial behaviours of cubic concrete specimens. The authors should be complimented for producing this detailed paper of interest for the discusser, who would like to offer some comments for the authors' consideration and response, mainly about the size effect on concrete compressive strength and concrete modulus of elasticity.

Regarding the effect of cube dimension on compressive strength, the authors found that compressive strength decreases if the cube dimension increases when DCBs are used. However, it has been noted that, for cylindrical specimens, the use of DCBs may induce a slightly stronger size effect on relative compressive strength, based on the compressive strength of specimens with a certain dimension (Wu et al., 2014). Can the authors clarify this for cubic specimens?

The authors pointed out that there is a size effect law (shown in Figure 4 of the original paper) that implies a slight size effect on compressive strength for cubic specimens whose dimension is below a certain threshold and a stronger size effect when the dimension is over this threshold. A threshold of $323.80 \mathrm{~mm}$ was established in Equation 3. Accordingly, the tested 150-300 mm cubic specimens should show less size effect than the 400$600 \mathrm{~mm}$ cubic specimens. However, it seems that Figure 5 shows a stronger size effect for the former. Can the authors explain this fact to offer a better understanding?

The authors have concluded that the effect of cube dimension on the modulus of elasticity of specimens including DCBs is unclear. Unclear effects have also been observed with cylindrical specimens (Wu et al., 2014). However, it is worth noting that the modulus of elasticity can be related to compressive strength, and a size effect law for the modulus of elasticity by modifying the size effect law for compressive strength has been suggested by Elfahal and Krauthammer (2005). Therefore, an explanation is required as to why a size effect was observed on compressive strength but not on modulus of elasticity.

In addition, a marked influence of specimen size on the modulus of elasticity has been reported by Martí-Vargas et al. (2014a). Several series of prismatic specimens with different embedment lengths have been tested using the evolutionary computation for the automated design of algorithms (ECADA) test method (Martí-Vargas et al., 2006). Based on prestress loss due to elastic concrete shortening and transformed cross-section properties (Martí-Vargas et al., 2014b), an early concrete modulus of elasticity at prestress transfer for each specimen was obtained. Higher concrete modulus of elasticity values were obtained for larger specimen cross-sections. A coefficient to account for the specimen cross-section size effect on the modulus of elasticity has been proposed, which agrees with the Model Code (fib, 2010) predictions for concrete modulus of elasticity at prestress transfer. Therefore, this may disagree with the limited or unclear effects observed in the discussed paper, and more tests to clarify the influence of DCBs are desirable.

\section{Authors' reply}

\section{Question 1}

No cubic specimen made from fresh concrete (FC) alone was fabricated and tested in the work presented in the original paper. Therefore, at present, the size effect on relative compressive strength of cubes made from DCBs and FC cannot be compared with the size effect on relative compressive strength of cubes made from FC alone. This issue will be taken into account in future studies. 


\section{Question 2}

The size effect law was derived from dimensional analysis for geometrically similar members carried out by Bažant, and was illustrated in a logarithmic curve (Bažant, 1984). The authors' test results shown in Figure 5 in the original paper are expressed in a non-logarithmic curve, so the trend shown in the figure is a little different from the logarithmic curve given by Bažant. Replotting the test results in a logarithmic curve, as shown in Figure 13, it can be seen that the trend in Figure 13 agrees well with the logarithmic curve given by Bažant. According to Figure 13, the tested $150-300 \mathrm{~mm}(\log (150-300)=2 \cdot 18-2 \cdot 48)$ cubic specimens show less size effect than the $400-600 \mathrm{~mm} \quad(\log (400$ $600)=2 \cdot 60-2 \cdot 78)$ cubic specimens, as desired by the discusser.

Similarly, the test results for high-strength concrete (HSC) cylinders given by Elfahal and Krauthammer (2005) are plotted in Figure 14 in a non-logarithmic curve and Figure 15 in a logarithmic curve. Again, it can be seen that the trend shown in

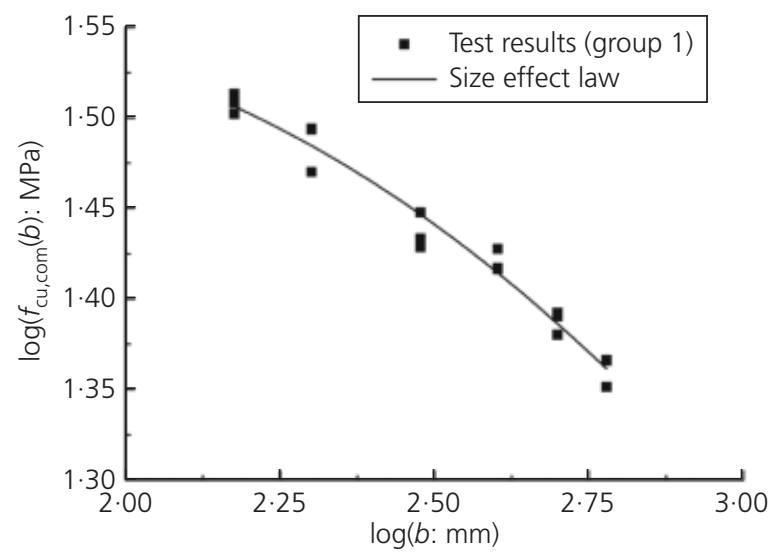

Figure 13. Variation of combined compressive strength with cube dimension for cubes made from DCBs and FC

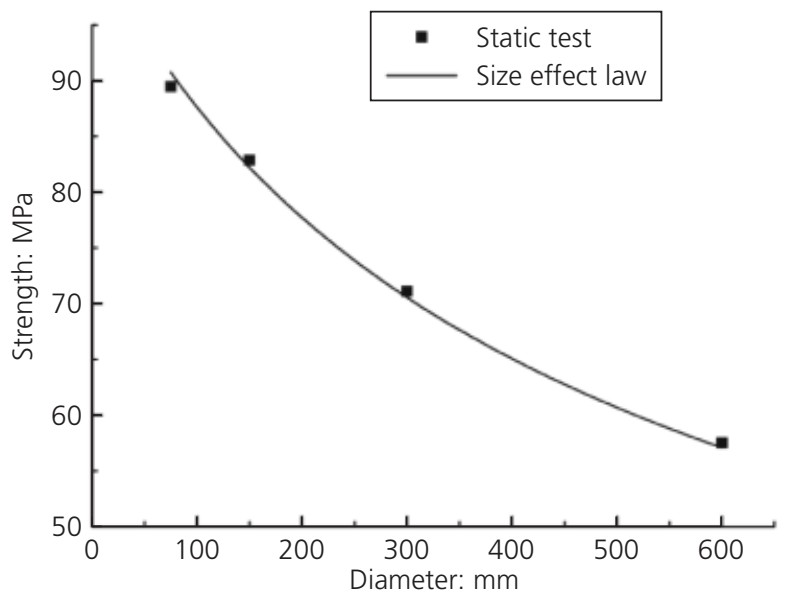

Figure 14. Test data and size effect law for HSC cylinders (based on Elfahal and Krauthammer (2005))

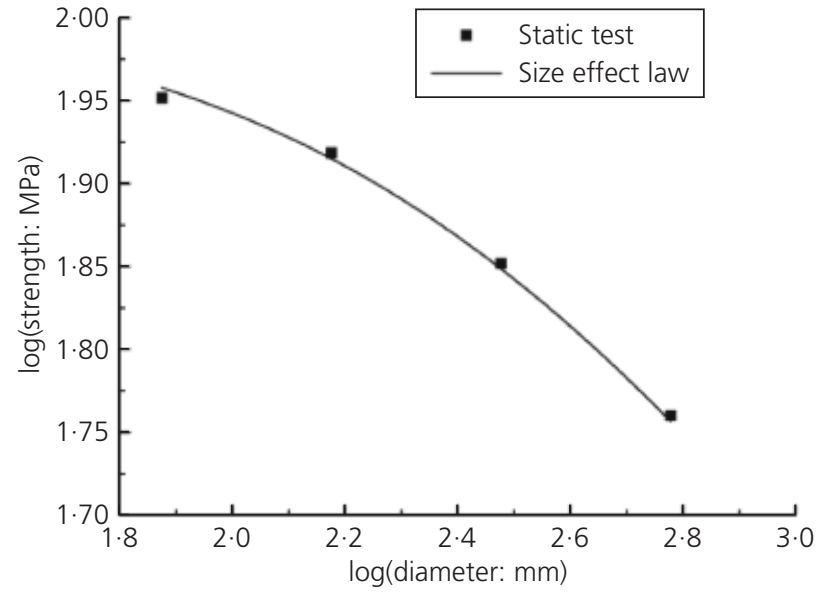

Figure 15. Test data and size effect law for HSC cylinders (based on Elfahal and Krauthammer (2005))

Figure 14 is a little different to that shown in Figure 15, and the latter is in accordance with the logarithmic curve given by Bažant (1984).

\section{Question 3}

In the original paper, the modulus of elasticity was determined using the compressive strain related to the middle $2 / 5$ height of the cubic specimen, and this strain is approximately uniform on the specimen's cross-section. On the other hand, the compressive strain of concrete decreases with increasing distance from the prestressing strand in the discusser's study (Martí-Vargas et al., 2014a), and the modulus of elasticity at prestress transfer is determined using the measured strain related to the surface of the specimen. The difference between the strain distribution in the original paper and that in the discusser's study may be one reason for the different influence of specimen size on the modulus of elasticity.

Referring to the experimental finding that a size effect has been observed on the compressive strength of cubic specimens made from DCBs and FC and not on the modulus of elasticity, at present the authors have no idea on the reason for this phenomenon. Whether the use of DCBs is the cause of this phenomenon needs to be investigated in detail in the future.

\section{REFERENCES}

Bažant ZP (1984) Size effect in blunt fracture: concrete, rock, metal. Journal of Engineering Mechanics ASCE 110(4): 518535.

Elfahal MM and Krauthammer T (2005) Dynamic size effect in normal- and high-strength concrete cylinders. ACI Materials Journal 102(2): 77-85.

fib (Fédération Internationale du Béton) (2010) Model Code. First Complete Draft, Volume 1. fib, Lausanne, Switzerland. 
Martí-Vargas JR, Serna-Ros P, Fernández-Prada MA, Miguel-Sosa PF and Arbeláez CA (2006) Test method for determination of the transmission and anchorage lengths in prestressed reinforcement. Magazine of Concrete Research 58(1): 21-29.

Martí-Vargas JR, Caro LA and Serna-Ros P (2014a) Size effect on strand bond and concrete strains at prestress transfer. $A C I$ Structural Journal 111(2): 419-429.

Martí-Vargas JR, García-Taengua E, Caro LA and Serna P (2014b)

Measuring specific parameters in pretensioned concrete members using a single testing technique. Measurement 49: 431-432.

Wu B, Liu CH and Yang Y (2013) Size effect on compressive behaviours of normal-strength concrete cubes made from demolished concrete blocks and fresh concrete. Magazine of Concrete Research 65(19): 1155-1167.

Wu B, Liu CH and Wu YP (2014) Compressive behaviors of cylindrical concrete specimens made of demolished concrete blocks and fresh concrete. Construction and Building Materials 53: 118-130. 